\title{
Microencapsulation of Essential Oils by Interfacial Polimerization Using Polyurea as a Wall Material
}

\author{
Ferrándiz Marcela1, Capablanca Lucía², Bou Eva², García David², Bonet Mª Ángeles², \\ Bartolome Luis ${ }^{3}$ \\ ${ }^{1}$ Biotechnology Research Group, Textile Research Institute (AITEX), Alcoy, Spain \\ ${ }^{2}$ Campus de Alcoy, Universitat Politècnica de València (UPV), Alcoy, Spain \\ ${ }^{3}$ Faculty of Science and Technology, Central Analysis Service (SGIker), University of the Basque Country \\ (UPV/EHU), Bilbao, Spain \\ Email:mferrandiz@aitex.es, lucafra@upvnet.upv.es, luis.bartolome@ehu.eus
}

Received 22 September 2015; accepted 23 November 2015; published 26 November 2015

Copyright (C) 2015 by authors and Scientific Research Publishing Inc.

This work is licensed under the Creative Commons Attribution International License (CC BY).

http://creativecommons.org/licenses/by/4.0/

(c) $\underset{\mathrm{EY}}{\mathrm{i}}$ Open Access

\section{Abstract}

An essential oil is the volatile lipophilic component extracted from plants. Microencapsulation systems protect the essential oil from degradation and evaporation, and, at the same time, allow a sustained release. This work analyses and characterizes the oregano and sage essential oil microcapsules prepared by interfacial polymerization technique, using polyurea as wall material. Several instrumental techniques are used: optical microscopy, size particle, Fourier transform infrared spectroscopy (FTIR), differential scanning calorimetry (DSC), Termo gravimetric analysis (TGA), spectrophotometry, antimicrobial test and chromatography. Results show that oregano and sage oil have antimicrobial properties, and their microencapsulation allows knowing that these properties remain inside the microcapsules.

\section{Keywords}

Oregano Oil, Sage Oil, Interfacial Polymerization, Polyurea

\section{Introduction}

The antiseptic qualities of aromatic and medicinal plants and their extracts had been recognized since antiquity, while attempted to characterize these properties in the laboratory date back to the early 1900s [1] [2]. Plant volatile oils (also called essential oils) are generally isolated from non-woody plant material by distillation methods, 
usually steam or hydrodistillation.

Essential oils have been shown to possess antibacterial, antifungal, antiviral insecticidal and antioxidant properties [3] [4]. Essential oils are a rich source of biologically active compounds.

There has been an increased interest in looking for antimicrobial properties of extracts from aromatic plants particularly essential oils [5]. Therefore, it is reasonable to expect a wide variety of plant compounds made of these oils with specific, as well as general antimicrobial activity and antibiotic potential [6].

Origanum vulgare (oregano) is widely accepted as one of herb spices with the strongest aroma and antioxidant activity [7]. Oregano has also been extensively studied due to its antimicrobial [8] [9] and insecticidal activity [10] [11].

Salvia officinalis (Sage) is one of the popular herbs known since ancient Roman times. The essential oil of sage species has various compositions depending on the genetic, climatic, seasonal, and environmental factors [12]. Some chemical compounds like flavonoids, terpenoids, and essential oils are present in different species of sage [13]. Essential oils are very important sources for the screening of anticancer, antimicrobial, antioxidant, and free radical scavenging agents [14] [15].

Essential oils can be used for many purposes, cosmetic, medicine, etc., but their application is limited because the main compounds of essential oils are volatile and chemically instable in the presence of oxygen, moisture and heat. The stability of essential oils can be enhanced through microencapsulation by different techniques. Various properties of active materials may be changed by encapsulation for instance, handling and flow properties can be improved by converting a liquid to a powdered encapsulated form.

Chemical microencapsulation methods are based on polymerisation or polycondensation mechanisms that may be implemented in a variety of different ways. Since the publication in 1959 by Morgan and his collaborators [16] of a series of papers on interfacial polymerization, this technology has gained a great interest in the industry, as it allows producing large quantity of microcapsules in a short time, getting high encapsulation efficiency [17].

In interfacial polymerization, it is possible to use different polymers like polyamide, polyurethane, polyurea as a shell material [18]. Polyurea is the most used polymer in interfacial polymerization for pesticide microcencapsulacion [19]-[21].

Polyurea is a type of elastomer which is obtained by the reaction between an isocyanate component and a polyamine, and it is not water-soluble. Its application field can differ considerably because of its solubility, size or thermal behaviour.

This study analyses microcapsules obtained by interfacial polymerization techniques using polyurea as a wall material and two different oils (oregano and sage) as core material. Different instrumental techniques have been used in order to characterize the obtained microcapsules and to demonstrate the encapsulation of the oils.

\section{Materials and Methods}

\subsection{Materials}

Oregano (Origanum vulgare leaf Oil) and sage (Salvia officinalis vulgare leaf Oil) essential oils (were supplied by Esencias Lozano, SA, Spain), originating from Europe, were used as the core material. 2,4-toluene diisocyanate (TDI, was supplied by Alfa Aesar) and 1,6-hexamethylenediamine (HDMI, was supplied by Panreac) were used as monomers for polyurea wall-forming materials. Tween 80 (was supplied by Panreac) and Poly (vinyl alcohol) (PVA, Mw, 1500) (was supplied by Sigma Aldrich) as the stabilizing agent.

\subsection{Experiment Design}

W/O (water/oil) emulsion was formed between organic solution with TDI oregano/sage oil and aqueous solution of $1 \%$ PVA tween 80 as a stabilizer. Table 1 shows the experimental parameters.

The emulsification was carried out at $6000 \mathrm{rpm}$ for $30 \mathrm{~min}$ with homogenizer (Benchtop, Pro. Scientific Inc., Oxford). Subsequently HDMI was added, the stirring speed was decreased to $600 \mathrm{rpm}$. After reaching $30^{\circ} \mathrm{C}$ and maintaining it (Fisher Scientific, Spain), and left in reaction for $120 \mathrm{~min}$ more, were formed the polyurea microcapsules. $150 \mathrm{~mL}$ of distilled water was added into the solution to disperse them. The obtained microcapsules were filtered, washed with $10 \%$ ethanol and dried in an oven at $40^{\circ} \mathrm{C}$ for 24 hours. 
Table 1. Optimal parameters in W/O emulsion.

\begin{tabular}{cccccccc}
\hline \multirow{2}{*}{ Experiment } & \multicolumn{3}{c}{ Aqueous phase (W) } & \multicolumn{3}{c}{ Oil phase (O) } \\
\cline { 2 - 7 } & Tween $\mathbf{8 0}(\mathbf{g})$ & $\mathbf{H}_{\mathbf{2}} \mathbf{O}(\mathbf{g})$ & PVA (g) $\mathbf{1} \%$ & HDMI (g) & Oil (g) & TDI (g) \\
\hline 1 & 15 & 250 & 10 & 10 & 10 & 100 & 30 \\
2 & 15 & 250 & 10 & 5 & 100 & 9 \\
3 & 15 & 250 & 10 & 5 & 40 & 9 \\
4 & 15 & 250 & & &
\end{tabular}

\section{Microcapsules Characterization}

\subsection{Scanning Electron Microscopy (SEM)}

For surface observation, a PHENON scanning electron microscope (FEI Company, United States) was used. Each sample was fixed on a standard sample holder and sputter coated with gold. Samples were then examined with suitable acceleration voltage and magnification.

\subsection{Particle Size Distribution}

The particle size distribution of the microcapsules was measured by a Mastersize E-3000 (Malvern, UK). The particle size was expressed as the equivalent volume diameter and three replicates were performed for each batch of microcapsules, to reduce error, an average curve was calculated and analyzed. Particles were dispersed in ethanol at a ratio of $1: 40 \mathrm{w} / \mathrm{v}$.

\subsection{Differential Scanning Calorimetry (DSC) Analysis}

Differential scanning calorimetry (Mettler-Toledo 821, Mettler-Toledo Inc., Schwerzenbach, Switzerland) was used to determinate the glass transition temperatures (Tg) of the dried microcapsules. Approximately $10 \mathrm{mg}$ of sample was prepared in aluminium pans in ambient atmosphere. The curves were obtained according to the following heating program: $0^{\circ} \mathrm{C}$ and $220^{\circ} \mathrm{C}$ at $5^{\circ} \mathrm{C} / \mathrm{min}$.

\subsection{Thermogravimetric Analysis (TGA)}

Thermogravimetric (TGA/SDTA 851, Mettler-Toledo Inc., Schwerzenbach, Switzerland) was used to determinate the stability of the microcapsules in high temperatures. Approximately $70 \mu \mathrm{l}$ of samples were prepared in aluminium pans. The thermal program was located between $0^{\circ} \mathrm{C}$ and $220^{\circ} \mathrm{C}$ at $10^{\circ} \mathrm{C} / \mathrm{min}$ under nitrogen gas with a flow rate of $60 \mathrm{~mL} \cdot \mathrm{min}^{-1}$.

\subsection{Fourier-Transform Infrared Spectroscopy (FTIR)}

Samples were analyzed in an Infrared spectra VARIAN FT-IR 670 with a $0.10 \mathrm{~cm}^{-1}$ resolution for each infrared spectrum. Spectra were collected in ATR mode.

\subsection{Chromatography}

A trace 1300 GC gas chromatograph equipped with a programmed split/splitless injector, an AI 1310 automatic sampler, and coupled to a single quadrupole mass detector (ISQ LT) was used to perform the GC -MS analysis (all from Thermo Scientific, San José, CA, USA). A Zebron ZB-5MS (30 m $\times 0.25 \mathrm{~mm}$ i.d., $0.25 \mu \mathrm{m}$ thickness) column was used (Phenomenex Torrance, CA, USA). Helium was used as carrier gas, at a flow rate of 1 $\mathrm{mL} / \mathrm{min}$.

The injector temperature was $250^{\circ} \mathrm{C}$. Samples were injected in the split mode 1:30 (w/v). The injection volume was $1 \mu \mathrm{l}$. The oven temperature was programmed as follows: $40^{\circ} \mathrm{C}$ for $2 \mathrm{~min}$, then $310^{\circ} \mathrm{C}$ at $7^{\circ} \mathrm{C} / \mathrm{min}$, maintained for $5 \mathrm{~min}$.

\subsection{Determination of Oil on Surface of Microcapsules}

Samples were washed with ethanol because the polyurea is insoluble in ethanol; the objective was to remove the superficial oil [22]. 
Approximately $1 \mathrm{~g}$ of sample was dispersed in $30 \mathrm{ml}$ of ethanol. Washing was performed in three consecutive steps of $10 \mathrm{~mL}$ collected extracts separately. The amount of essential oil surface was calculated through a formula used for successive extractions.

For the quantification of the oil it is necessary a calibration curve with patterns. For this, the necessary weights are taken (1 mg dissolved in $1 \mathrm{~mL}$ of Ethanol) to make stock solutions of $1000 \mathrm{mg} / \mathrm{mL}$ in each of the essential oils.

From these solutions the calibration solutions $(n=4)$ are performed for each of the compounds (sage and oregano). The concentration range is $0.001-1 \mathrm{~g} / \mathrm{g}$ of essential oil.

The measurements were made with a 7890 A gas chromatograph coupled to mass spectrometer (MS) XL 5975C inert. Agilent Technologies (CA, USA).

\subsection{Determination of Encapsulated Oil}

For this analysis was necessary to break the microcapsules and allow the release of the oil. $0.1 \mathrm{mg}$ of washed microcapsules were taken and were dissolved in $10 \mathrm{~mL}$ sulfuric acid $(\mathrm{pH}=0.8)$.

The monitoring of the release of the essential oil concentration of various compounds present in the oils was followed by analyzing samples collected during 120 hours. The measurements were made with a 7890 A gas chromatograph coupled to mass spectrometer (MS) XL 5975C inert. Agilent Technologies (CA, USA).

The release kinetics for each microcapsule is adjusted to order 1 , and from the equation constants it has been found liberation and life time media release.

\subsection{Antimicrobial Test}

Oregano and sage essential oils and the microcapsules were tested to determinate antifungal/antibacterial activity, based on Standard ASTM E 2149-13. The contact time of the material with fungi was $24 \mathrm{~h}$ and the culture medium used was Sabouraud Dextrosa Agar (Scharlab, Spain). The contact time of the material with bacteria was $24 \mathrm{~h}$ and the Culture medium used was plate Count Agar (Scharlab, Spain). The Incubation temperature was $35^{\circ} \mathrm{C} \pm 2{ }^{\circ} \mathrm{C}$.

\section{Results and Discussion}

\subsection{Scanning Electron Microscopy (SEM)}

The morphology of the microcapsules was studied by scanning electron microscopy (SEM). Figure 1 shows the micrograph of oregano microcapsules and Figure 2 shows the micrograph of sage microcapsules obtained by

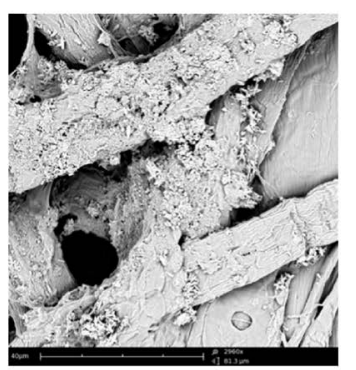

(a)

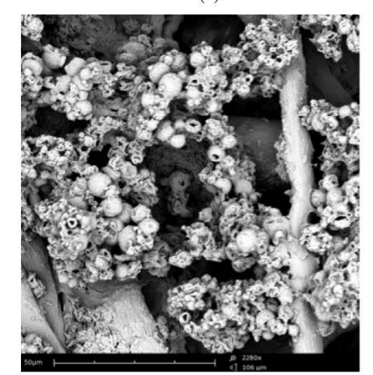

(c)

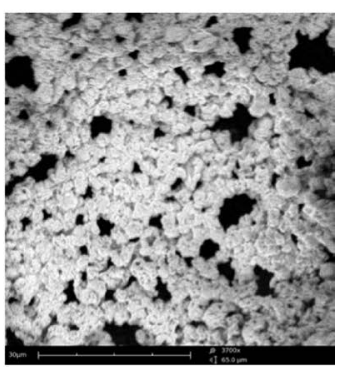

(b)

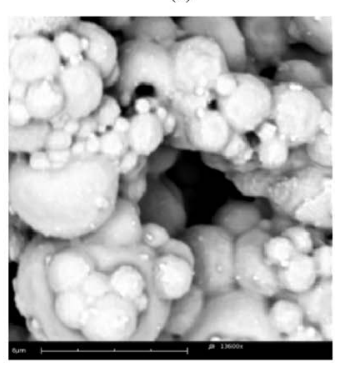

(d)

Figure 1. SEM photographs of oregano microcapsules (a) Experiment 1; (b) Experiment 2; (c) Experiment 3; (d) Experiment 4. 


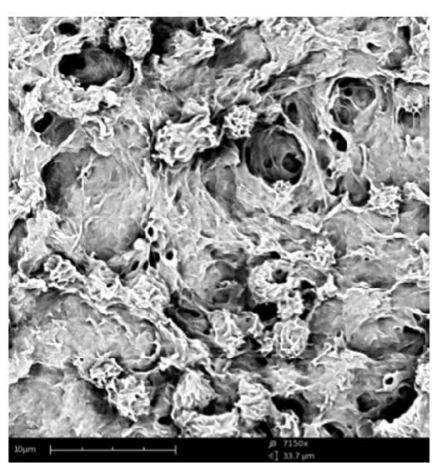

(a)

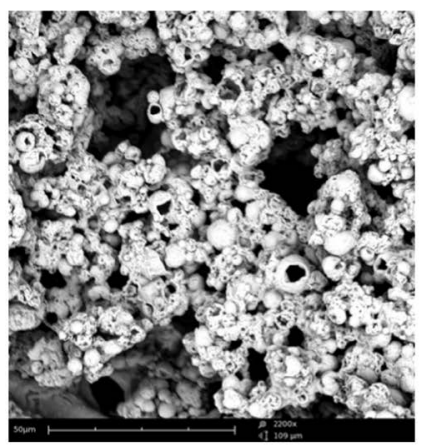

(c)

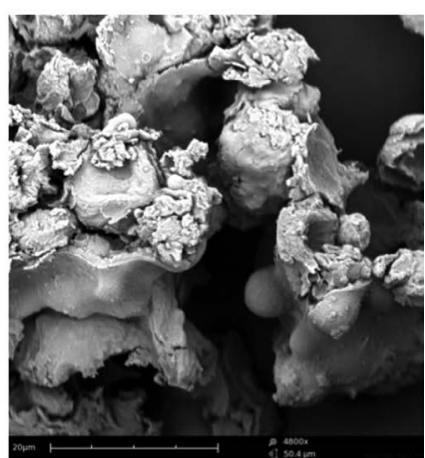

(b)

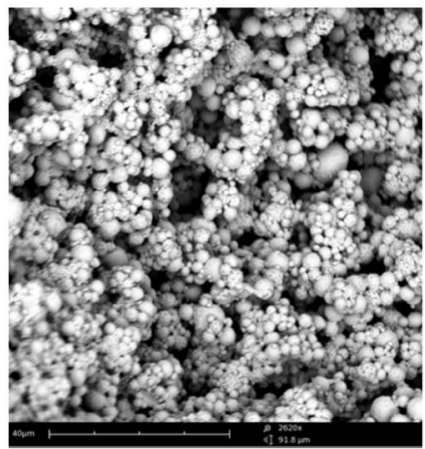

(d)

Figure 2. SEM photographs of sage microcapsules (a) Experiment 1; (b) Experiment 2; (c) Experiment 3; (d) Experiment 4.

different conditions.

Figure 1 and Figure 2 evidences that at lower concentrations of polymer (a) and (b) are formed microcapsules but are not entirely closed and their morphology is very irregular, however, at higher concentrations of polymer (c) the obtained microcapsules are spherical, in this case the concentration of oil used also influences the morphology, a higher concentration of microcapsuled oil shows the best morphology (d).

\subsection{Particle Size Distribution}

The SEM images analyzed previously demonstrated the spherical shape, and although the size was determined as variable and it could have been estimated, the particle size test offers objective and more precise measurements. Figure 3 represents the size distribution for microcapsules studied in this paper.

Depends on the oil the size distribution changes, oregano microcapsules are bigger than sage microcapsules. Its sizes reach $100 \mu \mathrm{m}$ while sage size microcapsules only reach $25 \mu \mathrm{m}$.

\subsection{Differential Scanning Calorimetry (DSC) Analysis}

Thermal analysis has been studied in order to determine the microcapsules thermal characteristics and predict their thermal behaviour.

Figure 4 and Figure 5 show the DSC thermograms of the oregano/sage oil, the polymer from the shell and the microcapsules containing both oils and the shell respectively. In Figure 4, it can be observed an endothermic transition at $190^{\circ} \mathrm{C}$, this temperature is attributed to the decomposition temperature of oregano oil. Microcapsules have and endothermic transition at $190^{\circ} \mathrm{C}$ and polyurea at higher temperatures than $220^{\circ} \mathrm{C}$. These temperatures demonstrate that drying temperature doesn't affect the microcapsules.

In Figure 5, it can be observed an endothermic transition at $150^{\circ} \mathrm{C}$; this temperature is attributed to the decomposition temperature of sage oil. Microcapsules have and endothermic transition at $130^{\circ} \mathrm{C}$ and polyurea at higher temperatures than $220^{\circ} \mathrm{C}$. These temperatures demonstrate that drying temperature doesn't affect the microcapsules. 


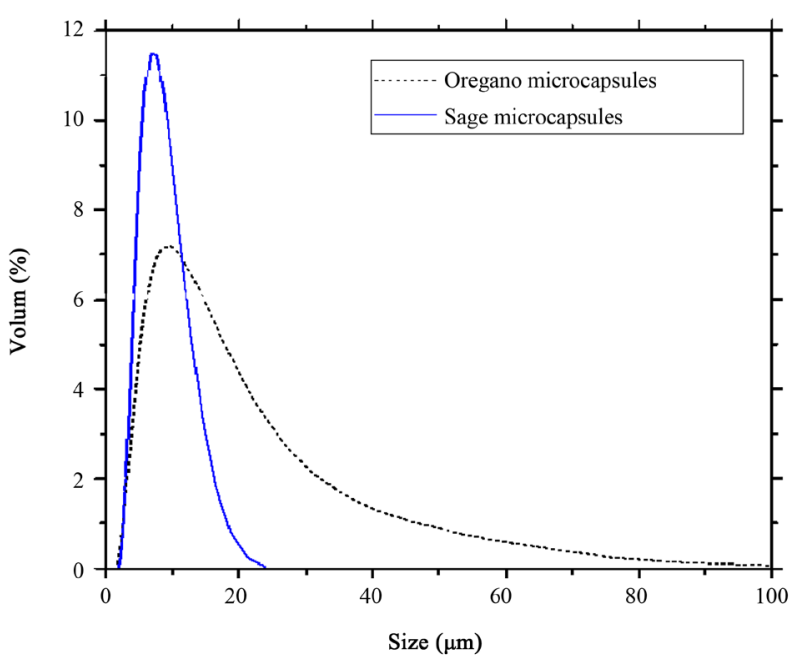

Figure 3. Particle size distribution of oregano and sage microcapsules.

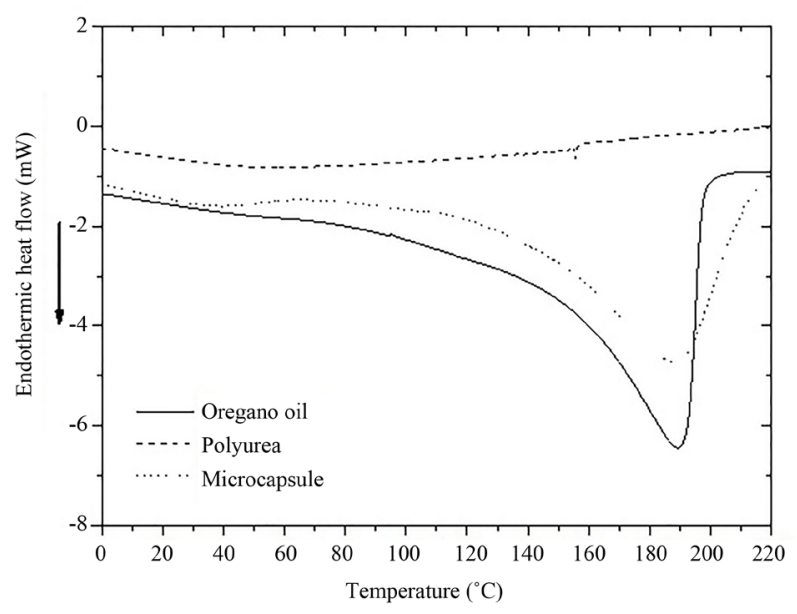

Figure 4. Differential scanning calorimetric diagram of oregano microcapsules.

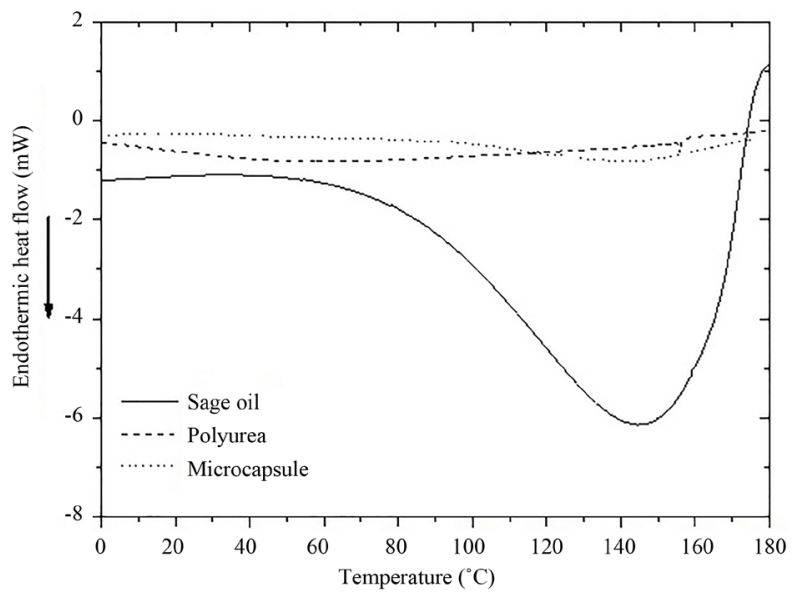

Figure 5. Differential scanning calorimetric diagram of sage microcapsules. 


\subsection{Thermogravimetric Analysis (TGA)}

Figure 6 and Figure 7 show the TGA thermograms of the oregano and sage oil, the polymer (shell) and microcapsules.

Oregano oil shows the decomposition temperature at $190^{\circ} \mathrm{C}$, and at $160^{\circ} \mathrm{C}$ starts to decompose. This results matches with DSC analysis. In Figure 6, it can be observed three curves corresponding to the oregano oil, polyurea as polymer used as wall material and oregano microcapsules obtained by interfacial polymerization with polyurea shell.

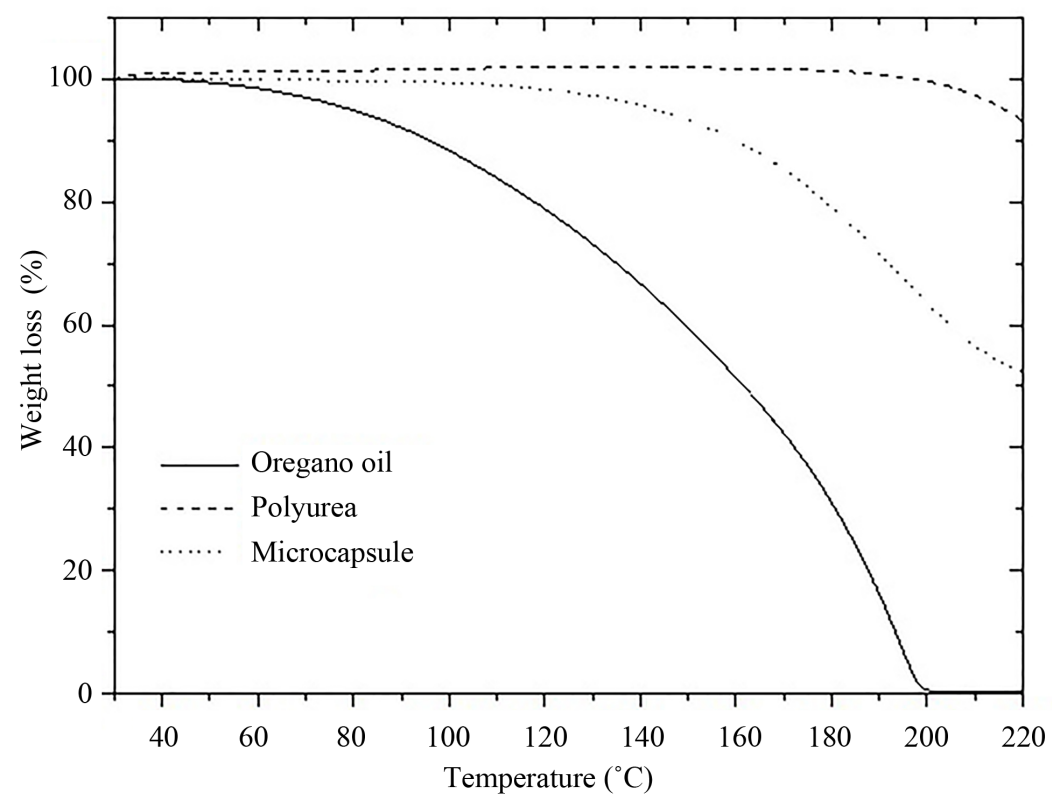

Figure 6. Three curves corresponding to the oregano oil, wall material and microcapsules.

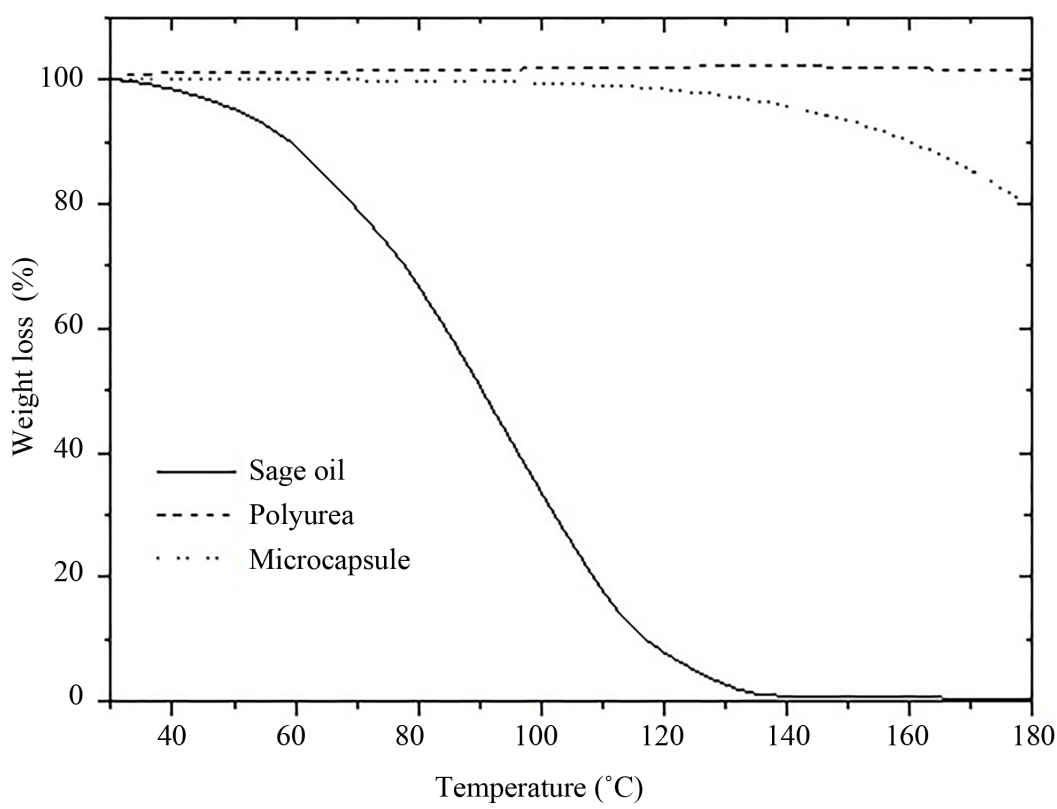

Figure 7. Three curves corresponding to the oregano oil, wall material and microcapsules. 
The weight loss starts at $140^{\circ} \mathrm{C}$ in microcapsules due to the indoor humidity evaporation, because the outdoor humidity is removed in the drying process to turn them into powder form. In polyurea shell, the weight loss starts at $200^{\circ} \mathrm{C}$, due to the outdoor humidity [23].

Sage oil shows that it is thermally stable up to $70^{\circ} \mathrm{C}$, and the decomposition temperature is at $95^{\circ} \mathrm{C}$. The weight loss starts at $110^{\circ} \mathrm{C}$ in microcapsules due to the indoor humidity evaporation, because the outdoor humidity is removed in the drying process to turn them into powder form.

\subsection{Fourier Transform Infrared Spectroscopy (FTIR)}

FTIR test was conducted in order to characterize the microcapsules. Figure 8 shows the spectra for three compounds, oregano oil, the polyurea and the microcapsules (oregano PYA).

When the study is centred in the region between $3800-2000 \mathrm{~cm}^{-1}$, two important zones can be observed. The first one is comprised between $3800-3100 \mathrm{~cm}^{-1}$ and is attributed to $\mathrm{O}-\mathrm{H}$ bonding, the second one is located around $3100-2600 \mathrm{~cm}^{-1}$ and is assigned to C-H stretching. All the samples show picks at both regions. Thus, it can be attributed to the oregano oil, which is composed in majority of carvacrol and timol [24]-[26].

When the oil has been encapsulated, the picks moved towards a different wavenumber. The polyurea shell shows a movement of the $\mathrm{O}-\mathrm{H}$ stretching pick towards a lower wavenumber due to the presence of $\mathrm{N}-\mathrm{H}$ in the polymer which is located around $3200-3300 \mathrm{~cm}^{-1}$. The pick attributed to polyurea oil is more sharpened than the rest of the picks.

On the other hand, Figure 9 shows the spectra for three compounds, sage oil, the polyurea and the microcapsules (sage PYA).

In the sage spectrum it can be observed different picks due to main compounds, at $2950 \mathrm{~cm}^{-1}$ which is attributed to $\mathrm{CH}_{3}$ stretching, at $1750 \mathrm{~cm}^{-1}$ which is assigned to $\mathrm{C}=\mathrm{O}$ stretching, in the region between $1390-1375$ $\mathrm{cm}^{-1}$ it finds C- $\left(\mathrm{CH}_{3}\right)_{2}$ group and at $750 \mathrm{~cm}^{-1}$ is attributed an aromatic group flexion, all this is characteristic to the camphor compound [24] [26].

Also appear in the spectrum bands characteristic to the compound 1,8-Cineol at: $1374 \mathrm{~cm}^{-1}$ due $\mathrm{CH}_{3}(\mathrm{CO})$, $1214 \mathrm{~cm}^{-1}$ produced by stretching of the COC group and between $984-843 \mathrm{~cm}^{-1}$ due to stretching of the CH groups [24].

\subsection{Chromatography}

Table 2 and Table 3 show the main components that were identified in the samples of oregano and sage essential oil by cromatography.

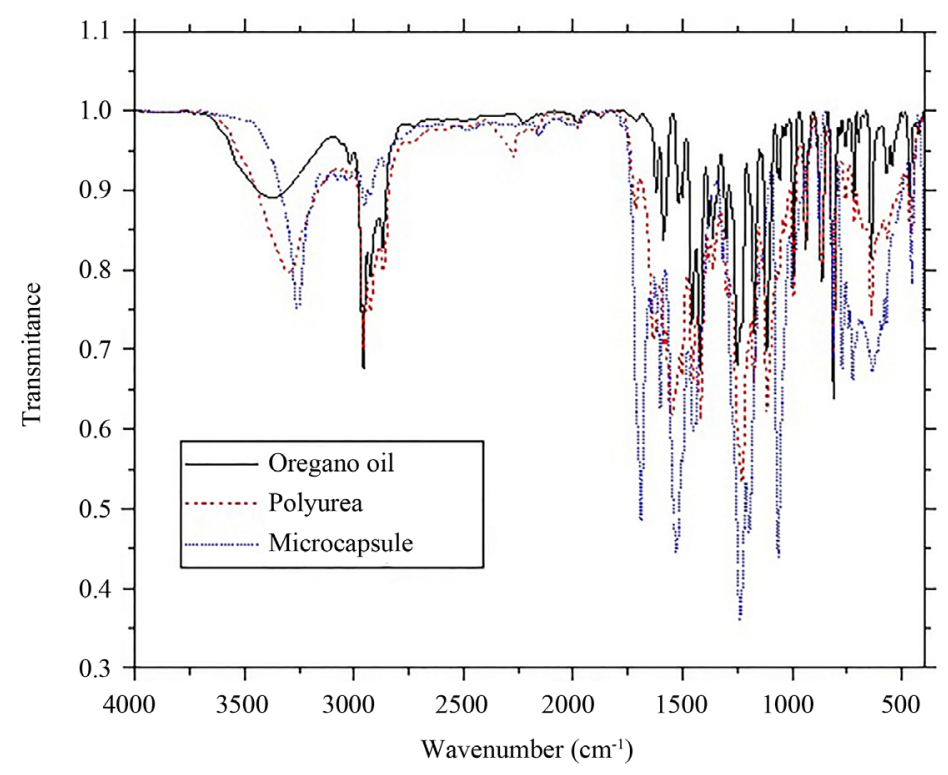

Figure 8. FTIR spectra from the oregano oil and microcapsules. 


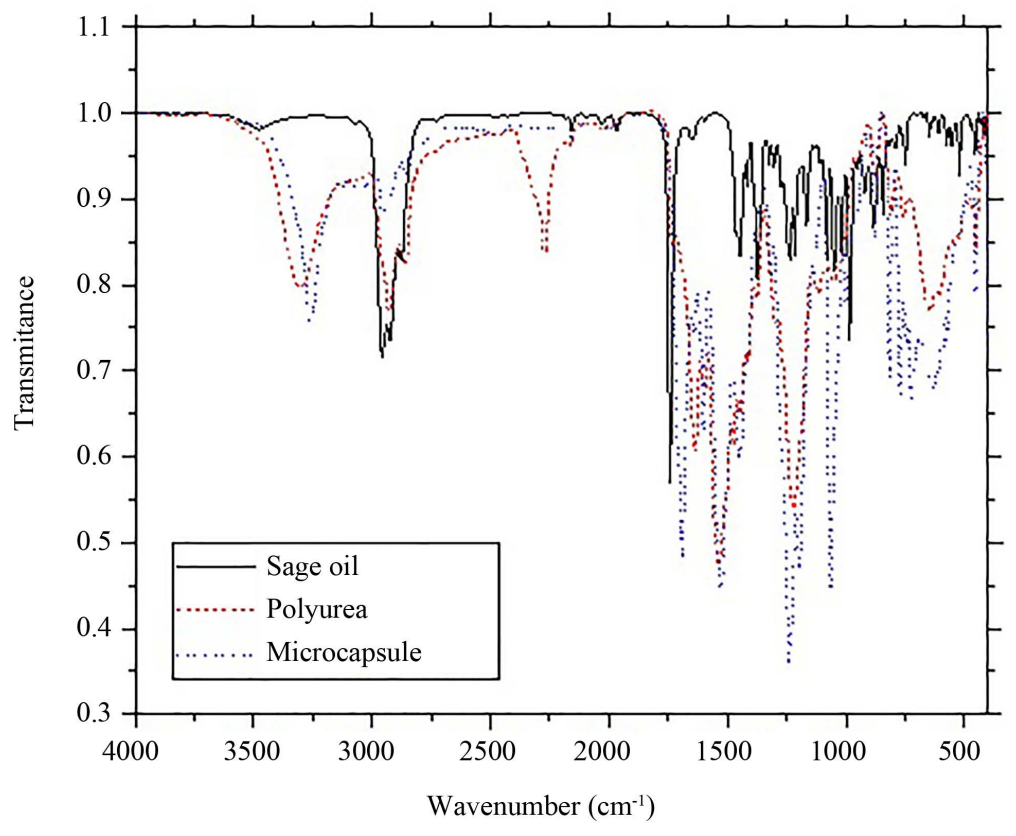

Figure 9. FTIR spectra from the sage oil and microcapsules.

Table 2. Components identified in the samples of oregano oil.

\begin{tabular}{ccc}
\hline $\mathbf{t R}$ & Library/ID & $\mathbf{m} / \mathbf{z}$ \\
\hline 5.47 & Alpha-Phellandrene & 93 \\
5.68 & Cyclohexene,1-methyl-4-(1-methylethylidene)- & 93 \\
6.63 & Gamm-Tepinene & 93 \\
6.97 & $\alpha$-Cymene & 119 \\
10.68 & 1,6-Octadien-3-ol, 3,7-dimethyl- & 93 \\
11.39 & Caryophyllene & 93 \\
17.49 & Thymol & 135 \\
17.78 & Phenol, 2,3,5,6-tetramethyl & 135 \\
\hline
\end{tabular}

Table 3. Components identified in the samples of sage oil.

\begin{tabular}{ccc}
\hline $\mathbf{t R}$ & Library/ID & $\mathbf{~ m} / \mathbf{z}$ \\
\hline 5.35 & Bicyclo[3.1.0]hex-2-ene, 4-methyl-1-(1- & 80 \\
5.88 & D-Limonene & 99 \\
6.08 & Beta.-Phellandrene & 94 \\
10.38 & Camphor & 97 \\
10.77 & 1,6-Octadien-3-ol, 3,7-dimethyl-,2-aminobenzoate & 91 \\
12.60 & Endo-borneol & 97 \\
\hline
\end{tabular}

\subsection{Determination of Oil on Surface of Microcapsules}

The determination of oils on microcapsules surfaces was performed starting from a calibration curve with different concentrations of oil in ethanol. The compounds selected in the chromatography study were used.

Table 4 shows the results of oil on surface microcapsules. 
Table 4. Oil on the surface of microcapsules.

\begin{tabular}{cc}
\hline Oil & $\boldsymbol{\mu g} \cdot \mathbf{m L}^{-\mathbf{1}}$ \\
\hline Oregano & 0.16 \\
Sage & 0.6 \\
\hline
\end{tabular}

\subsection{Determination of Encapsulated Oil}

In the study of oil release was taken into account the percentage of theoretical encapsulated essential oil (w/w) and the oil calculated on the microcapsule surface.

Theoretical encapsulated essential oil is 4 ppm (if all the oil had been encapsulated)

$$
40 g_{\text {oil }} / 100 g_{\text {Total }}=0.40 \%
$$

$0.1 \mathrm{mg}$ of encapsulated $(0.40 \% \mathrm{w} / \mathrm{w})$ in $10 \mathrm{~mL}$ of the solution $(\mathrm{pH}=0.8)=4.0 \mu \mathrm{g} \cdot \mathrm{mL}^{-1}$.

Monitoring of the release of microcapsules was studied analyzing the concentration of various compounds distributed along the chromatogram. Polyurea membrane was deteriorated very quickly, therefore the oil release is produced in the first period of time. Figure 10 and Figure 11 showed the controled release of oregano and sage microcapsules respectively.

Given release kinetic equations can be attached to different kinetic orders (order 0 , order 1 , order 2). The best regression was obtained for one order kinetic release (1)

$$
\left[C_{\text {free oil }}\right]=\left[C_{\text {initial oil }}\right]-k t
$$

where:

$C=$ concentration;

$T=$ time.

The constants found for each of the oils in each of the cases were as follows:

$$
\begin{gathered}
K^{\text {Oregano }}=0.274 \\
K^{\text {Sage }}=0.109
\end{gathered}
$$

From constants has been possible to determinate the half-life time $\left(T_{1 / 2}\right)$ release (in hours) using an aggressive solution to break the shell (2).

$$
\begin{gathered}
T_{1 / 2}=\ln 2 / k \\
T_{1 / 2}^{\text {Oregano }}=2.53 \mathrm{~h} \\
T_{1 / 2}^{\text {Sage }}=6.36 \mathrm{~h}
\end{gathered}
$$

According to the results, it is possible to conclude that the essential oils (oregano and sage) are encapsulated and that the oils are released completely when the membrane is broken, yielding different half-lives of retention of oils in the solutions before complete volatilization.

\subsection{Antimicrobial Test}

Oregano and sage essential oil were tested as an antimicrobial and antifungal. They presented an excellent reduction at the bacteria and fungi test. Results are showed in Table 5.

\section{Conclusions}

In this study, the encapsulation of essential oils is studied by using polyurea as a shell material by interfacial polimerization. Interfacial polymerization allows obtaining spherical microcapsules with an inside core of active ingredient (oil). However, the study of oil characteristics offers a big difference in the microcapsules size or amount of oil encapsulated.

FTIR analysis demonstrates that the polymerization process for the wall material is correctly conducted and 


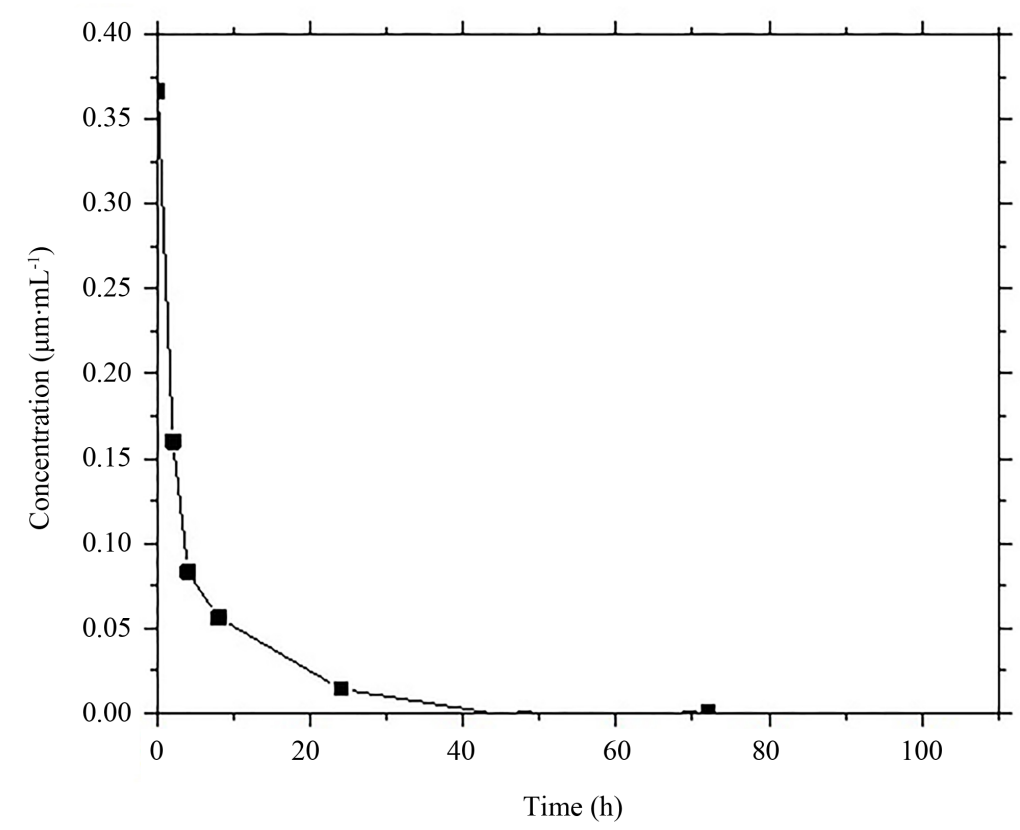

Figure 10. Oregano oil release of microcapsules.

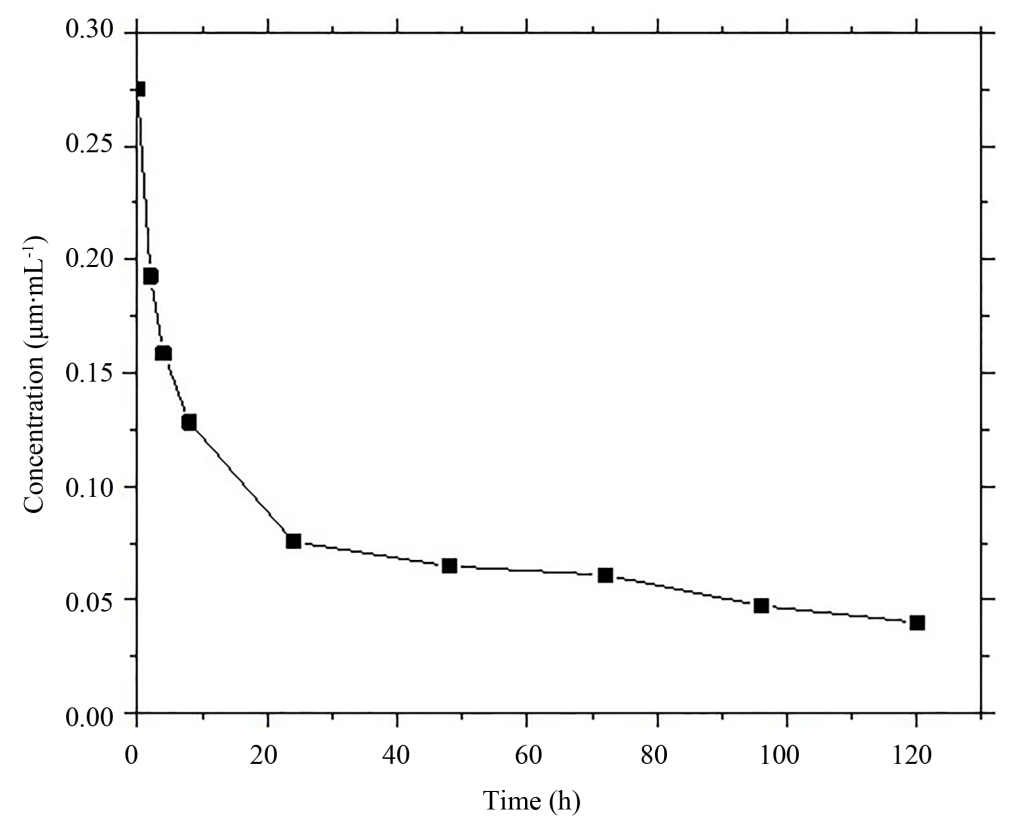

Figure 11. Sage oil release of microcapsules.

Table 5. Antimicrobial test.

\begin{tabular}{cccccc}
\hline \multirow{2}{*}{ Microorganisms } & Origin & \multicolumn{3}{c}{ \% Reduction (cfu/ml) } \\
\cline { 3 - 5 } & & Oregano oil & Oregano oil microcapsules & Sage oil & Sage oil microcapsules \\
\hline Penicillium Citrinum & ATCC 1109 & 99.99 & 99.00 & 99.99 \\
Rhizopus Oryzae & ATCC 11145 & 99.99 & 99.99 & 99.99 \\
Salmonella Enterica & ATCC 14028 & 99.99 & 99.99 & 99.99 & 98.00 \\
Escherichia Coli & ATCC 25922 & 99.99 & 99.99 & 99.99 \\
\hline
\end{tabular}


oregano and sage oils are present in the microcapsules.

Thermal analysis shows that polyurea microcapsules begin their degradation at lower temperatures than free oil. This should be taken into consideration when they are used in a procedure which involves thermal treatment.

Chromatography analysis allows evaluating the oil on microcapsules surface and the oil present in the microcapsules. Therefore, the main components in the oil are controlled by chromatography, in each analyze obtaining the oil on surface, which it is different in oregano microcapsule and sage microcapsule, and this difference can be due to the size of the microcapsules. The size of sage microcapsules is smaller than the ones of oregano, but the raw material used in the encapsulation process is the same. This can affect the amount of encapsulated oil. In sage microcapsules, more oil is not encapsulated comparing with oregano oil, because the microcapsules are smaller.

Oregano and sage oil have presented antimicrobial properties; these properties are maintained after the encapsulation, as showing the results of the antimicrobial test. Oregano microcapsules have a better antimicrobial behavior than sage microcapsules, and that is due to the size of the microcapsules and the oil that is contained inside the microcapsules.

Both oils have interesting properties: antioxidant activity, antimicrobial and insecticidal activity among others and can be used in many applications such as: papermaking, cosmetic, food or textile industry. In this paper, microcapsules have been characterized and their restrictions during manufacturing such as thermal conditions have been established in addition to demonstrate that the oil is contained in the microcapsules by different techniques (FTIR and chromatography).

\section{Acknowledgements}

The authors thank IVACE (Institut Valencià de Competitivitat Empresarial, Spain) and FEDER (Fondo Europeo de Desarrollo Regional, Europe) for the financial support.

\section{References}

[1] Martindale, W.H. (1910) Essential Oils in Relation to Their Antiseptic Powers as Determined by Their Carbolic Coefficients. Perfumery and Essential Oil Research, 1, 266-296.

[2] Hoffman, C. and Evans, A.C. (1911) The Uses of Spices as Preservatives. Journal of Indian Engineering and Chemistry, 3, pp. 835-838. http://dx.doi.org/10.1021/ie50035a016

[3] Burt, S.A. (2004) Essential Oils: Their Antibacterial Properties and Potential Applications in Foods: A Review. International Journal of Food Microbiology, 94, 223-253. http://dx.doi.org/10.1016/j.ijfoodmicro.2004.03.022

[4] Kordali, S., Kotan, R., Mavi, A., Cakir, A., Ala, A. and Yildirim, A. (2005) Determination of the Chemical Composition and Antioxidant Activity of the Essential Oil of Artemisia dracunculus and of the Antifungal and Antibacterial Activities of Turkish Artemisia absinthium, A. dracunculus, Artemisia santonicum, and Artemisia spicigera Essential Oils. Journal of Agricultural and Food Chemistry, 53, 9452-9458. http://dx.doi.org/10.1021/jf0516538

[5] Milhau, G., Valentin, A., Benoit, F., Mallie, M., Bastide, J., Pelissier, Y. and Bessiere, J. (1997) In Vitro Antimicrobial Activity of Eight Essential Oils. Journal of Essential Oil Research, 9, 329-333. http://dx.doi.org/10.1080/10412905.1997.10554252

[6] Darokar, M.P., Mathur, A., Dwivedi, S., Bhalla, R., Khanuja, S.P.S. and Kumar, S. (1998) Detection of Antibacterial Activity in the Floral Petals of Some Higher Plants. Current Science, 75, 187.

[7] Kulisica, T., Radonic, A., Katalinic, V. and Milosa, M. (2004) Use of Different Methods for Testing Antioxidative Activity of Oregano Essential Oil. Food Chemistry, 85, 633-640. http://dx.doi.org/10.1016/j.foodchem.2003.07.024

[8] Seydim, C. and Sarikus, G. (2006) Antimicrobial Activity of Whey Protein Based Edible Films Incorporated with Oregano, Rosemary and Garlic Essential Oils. Food Research International, 39, 639-644. http://dx.doi.org/10.1016/j.foodres.2006.01.013

[9] Lambert, R.J., Skandamis, P.N., Coote, P.I. and Nychas, G. (2001) A Study of the Minimum Inhibitory Concentration and Mode of Action of Orégano Essential Oil, Thymol and Carvacrol. Journal of Applied Microbiology, 91, 453-462. http://dx.doi.org/10.1046/j.1365-2672.2001.01428.x

[10] Karpouhtsis, O., Pardali, E., Feggou, E., Kokkini, S., Scouras, Z.G. and Mavragani-Tsipidou, P. (1998) Insecticidal and Genotoxic Activities of Oregano Essential Oils. Journal of Agricultural and Food Chemistry, 46, 1111-1115. http://dx.doi.org/10.1021/jf9708220

[11] Karioti, A., Milošević-Ifantis, A., Pachopos, N., Niryiannaki, N., Hadjipavlou-Litina, D. and Skaltsa, H. (2015) Antioxidant, Anti-Inflammatory Potential and Chemical Constituents of Origanum dubium Boiss., Growing Wild in Cyprus. 
Journal of Enzyme Inhibition and Medicinal Chemistry, 30, 38-43.

[12] Hadri. A., Gomez del Rio, M., Sanz, J., Coloma, A., Idaomar, M. and Ozanas, B. (2010) Cytotoxic Activity of $\alpha$-Humulene and Transcaryo-Phyllene from Salvia officinalis in Animal and Human Tumor Cells. Anales de la Real Academia Nacional de Farmacia, 76, 343-356.

[13] Ayatollahi, A., Shojaii, A., Kobarfard, F., Mohammadzadeh, M. and Choudhary, M. (2009) Two Flavones from Salvia leriaefolia. Iranian Journal of Pharmaceutical Research, 8, 179-184.

[14] Hussain, A., Anwar, F., Iqbal, T. and Bhatti, I. (2011) Antioxidant Attributes of Four Lamiaceae Essential Oils. Pakistan Journal of Botany, 43, 1315-1321.

[15] Hamidpour, M., Hamidpour, R. and Hamidpour, S. (2014) Chemistry, Pharmacology, and Medicinal Property of Salvia (Sage) to Prevent and Cure Illnesses Such as Obesity, Diabetes, Depression, Dementia, Lupus, Autism, Heart Disease, and Cancer. Journal of Traditional and Complementary Medicine, 4, 82-88. http://dx.doi.org/10.4103/2225-4110.130373

[16] Morgan, P.W. and Kwolek, S.L. (1959) Interfacial Polycondensation. II. Fundamentals of Polymer Formation at Liquid Interfaces. Journal of Polymer Science, 40, 299-327. http://dx.doi.org/10.1002/pol.1959.1204013702

[17] Carvalho, I.T., Estevinho, B.N. and Santos, L. (2015) Application of Microencapsulated Essential Oils in Cosmetic and Personal Healthcare Products-A Review. International Journal of Cosmetic Science, In Press.

[18] Dubey, R., Shami, T.C. and Bhasker Rao, K.U. (2009) Microencapsulation Technology and Applications. Defence Science Journal, 59, 82-95.

[19] Hashemi, S.A. and Zandi, M. (2001) Encapsulation Process in Synthesizing Polyurea Microcapsules Containing Pesticide. Iranian Polymer Journal, 10, 265-270.

[20] Moghbeli, M.R., Abedi, V. and Dekamin, M.G. (2011) Microencapsulation of Ethion by Interfacial Polymerization Utilizing Potassium Phthalimide- $N$-Oxyl (PPINO) as a Promoter. Iranian Journal of Chemical Engineering, 8, 34-42.

[21] Kobašlija, M. and Mcquade, T. (2006) Polyurea Microcapsules from Oil-in-Oil Emulsions via Interfacial Polymerization. Macromolecules, 39, 6371-6375. http://dx.doi.org/10.1021/ma061455x

[22] Báez-González, G.M., Alanís Guzmán, M., Regalado Méndez, A. and Rendón Galindo, A. (2010) Eficiencia de encapsulación del aceite de linaza utilizando goma de mezquite y quitosano como materiales de pared. Proceedings of the XII Congreso nacional de ciencia y tecnología de alimentos, Guanajuato, Jueves 27 y Viernes 28 de Mayo de 2010, $1-5$.

[23] Osorio, C., Acevedo, B., Carriazo, J., Winterhalter, P. and Morales, A.L. (2010) Microencapsulation by Spray-Drying of Anthocyanin Pigments from Corozo (Bactris guineensis) Fruit. Journal of Agriculture and Food Chemistry, 58, 6977-6985. http://dx.doi.org/10.1021/jf100536g

[24] Al-Sheibany, I.S., Kadhim, K.H. and Abdullah, A.S. (2005) Qualitative and Quantitative Evaluation of Some Organic Compounds in Iraqi Thyme. National Journal of Chemistry, 19, 366-379.

[25] Kumar, S., Panner, R. and Sivakumar, T. (2010) Isolation, Characterisation and Formulation Properties of a New Plant Gum Obtained from Mangifera indica. International Journal of Pharmaceutical and Biomedical Research, 1, 35-41.

[26] Schulz, H., Özkan, G. and Barkansa, M. (2005) Characterisation of Essential Oil Plants from Turkey by IR and Raman Spectroscopy. Vibrational Spectroscopy, 39, 249-256. http://dx.doi.org/10.1016/j.vibspec.2005.04.009 